\title{
Penggunaan System Usability Scale (SUS) Sebagai Evaluasi Website Berita Mobile
}

\author{
Abdurrahman Sidik, S.Sn, M.Ds \\ Fakultas Teknologi Informasi, \\ Universitas Islam Kalimantan Muhammad Arsyad Al-Banjari \\ abdurrahmansidik30@gmail.com
}

\begin{abstract}
ABSTRAK
Seiring perkembangan zaman, teknologi mengubah pola interaksi manusia, salah satunya adalah website berita mobile. Ada banyak sekali website berita mobile yang berkembang di Indonesia. Semua website berita tersebut berusaha mencapai dan memberikan yang terbaik kepada masyarakat agar tetap diminati. Sejalan dengan konsep tersebut, Brooke mengembangkan System Usability Scale (SUS) untuk mengetahui kegunaan dan fungsi dari sebuah produk dan juga jasa. Brooke berpendapat bahwa SUS berguna untuk menilai kegunaan dan fungsi dari berbagai macam produk termasuk salah satunya adalah Website. Penelitian ini bertujuan untuk mengadaptasi System Usability Scale (SUS) dan menguji validitas dan juga reliabilitas dari SUS ini sehingga dapat diterapkan untuk menilai fungsi dan kegunaan dari website berita mobile. Menimbang kepopuleran dari DetikCom sebagai salah satu website berita mobile di Indonesia, peneliti memilih DetikCom sebagai sample objek dari SUS ini. Subjek penelitian ini berjumlah 55 orang $(N=55)$ dengan usia responden minimum 18 tahun, dan maksimal 35 tahun. Hasil reliabilitas dan validitas pada SUS menunjukkan bahwa kuesioner SUS memiliki tingkat reliabilitas yang cukup baik.
\end{abstract}

Kata Kunci: Smartphone, System Usability Scale, Usability, Website

\section{PENDAHULUAN}

Percepatan perkembangan teknologi dalam bidang Teknologi Informasi dan Komunikasi (TIK) merupakan kenyataan yang terjadi pada saat ini. Perkembangan tersebut telah menyebabkan sejumlah pengaruh dalam kehidupan manusia, salah satunya adalah penggunaan internet. Internet mengubah pola interaksi manusia yang terlibat di dalamnya, serta mengubah cara seseorang memperoleh informasi. Perubahan pola interaksi manusia tersebut melahirkan konsep baru, yaitu website berita mobile. Jika dulu seseorang ingin mengetahui peristiwa atau berita penting terhangat seputar kehidupan manusia, maka ia akan membeli surat kabar. Namun sekarang, pengguna internet dapat mengakses website berita secara gratis melalui smartphone, berita yang disajikan pun beragam dan terkini tanpa harus menunggu surat kabar terbit esok harinya. Website berita sengaja menggunakan banyak tautan berita agar pengguna dapat mengklik halaman lain dalam website untuk menemukan informasi rinci [1].
Semakin banyak pengguna mengakses website berita, maka akan semakin banyak keuntungan yang didapatkan.

Namun, banyak pula di antara website berita tersebut yang tidak dapat memenuhi tujuan awal kenapa website tersebut dibuat dan bahkan banyak yang mengecewakan pengguna yang mengaksesnya. Menurut penelitian yang dilakukan oleh User Interface Engineering, Inc. [2] diketahui bahwa $60 \%$ waktu terbuang karena orang tidak bisa menemukan informasi yang ingin didapatnya pada suatu website dan hal ini berdampak pada penurunan produktivitas, meningkatkan frustasi dan bentuk kerugian lainnya. Berdasarkan fakta tersebut, pengguna umumnya memberikan penilaian subjektif bahwa website berita mobile tersebut sudah tidak pantas untuk dikunjungi lagi. Jika hal ini terjadi kepada banyak pembaca, maka sudah dapat dipastikan bahwa website berita tersebut akan ditinggalkan banyak orang sehingga akan berakibat gagalnya pencapaian tujuan awal pembuatan website berita mobile itu sendiri. Kerugian lain yang bisa terjadi 
adalah kehilangan keuntungan yang mungkin dapat diperoleh, atau bahkan berakibat paling buruk berupa ditutupnya website tersebut, citra buruk dari website berita yang bermutu rendah dibandingkan kompetitornya. Berdasarkan hasil studi yang dilakukan Forrester Research [2], dinyatakan bahwa sekitar $50 \%$ dari potential sales hilang karena pengguna tidak bisa menemukan informasi dan $40 \%$ dari pengguna tidak kembali lagi mengunjungi website karena pengalaman buruk ketika pertama kali mengunjungi website tersebut.

Usability berasal dari kata usable yang berarti dapat digunakan dengan baik. Usability secara umum dapat diartikan sebagai proses optimasi interaksi antara pengguna dengan system yang dapat dilakukan dengan interaktif. Usability menjadi aspek penting dalam keberhasilan sebuah website. Nielsen mendefinisikan usability sebagai suatu pengalaman pengguna dalam berinteraksi dengan aplikasi atau website sampai pengguna dapat mengoperasikannya dengan mudah dan cepat [3]. Usability akan berdampak pada pengalaman pengunjung yang paling mendasar, mengacu pada bagaimana seseorang menggunakan website tersebut secara mudah, khususnya bagi seseorang yang pertama kali mengunjungi atau menggunakan website [4].

Untuk melihat seberapa besar keberhasilan website diperlukan sebuah pengukuran untuk mengukur usability pada website. Ada banyak kuesioner yang tersedia untuk mengukur usability, salah satunya adalah System Usability Scale (SUS) [5]. SUS adalah alat ukur yang menilai usability suatu produk. Ada beberapa karakteristik dari SUS yang membuat menarik dan berbeda dari kuesioner lain. Pertama, SUS terdiri dari sepuluh pertanyaan, sehingga relatif cepat dan mudah bagi responden untuk menyelesaikan. Kedua, SUS menggunakan teknologi agnostik, yang berarti dapat digunakan secara luas dan mengevaluasi hampir semua jenis interface, termasuk website, smartphone, respon suara interaktif (IVR), systems (touch-tone dan speech), TV, dll. Ketiga, hasil kuesioner adalah nilai tunggal, mulai dari skor 0 sampai 100 , dan relatif mudah dipahami oleh berbagai disiplin, baik individu maupun kelompok.

\section{METODE PENELITIAN}

Dalam penelitian ini peneliti akan menguji reliabilitas dan validitas System Usability Scale (SUS) dengan menggunakan SPSS 16. SUS akan disebar secara online dan acak kepada 55 orang responden $\quad(\mathrm{N}=55)$. Menurut Asosiasi Penyelenggara Jasa Internet Indonesia (APJII) yang bekerjasama dengan PusKaKom UI [6] pengguna Internet paling aktif di Indonesia yaitu usia 18-35 tahun, dengan total persentase sebesar $82.8 \%$. Untuk itu, peneliti akan menggunakan sampel usia 18-35 tahun sebagai objek penelitian. Dari 55 responden tersebut, 30 responden adalah perempuan dan 25 responden sisanya adalah lakilaki.

Responden adalah pembaca berita aktif yang mempunyai smartphone pribadi. Peneliti membatasi ukuran layar smartphone yang digunakan responden untuk mengakses website berita mobile. Menurut Phone Scoop [7] smartphone memiliki layar dari 2,45 inch hingga 5,2 inch, artinya jika pengguna mempunyai layar smartphone di bawah 2,45 inch dan di atas 5,2 inch maka tidak termasuk dalam data yang akan dianalisis.

Website berita mobile yang dijadikan sampel adalah DetikCom (http://m.detik.com). Pemilihan website tersebut didasarkan pada pertimbangan bahwa DetikCom adalah portal website yang berisi berita dan artikel terkini di Indonesia. Berdasarkan statistik Alexa [8], DetikCom adalah website berita peringkat satu terpopuler berdasarkan jumlah kunjungannya sejak tahun 1998 hingga 2016. Sedangkan pada peringkat dunia DetikCom meraih peringkat ke-166 dengan rata-rata waktu akses sebanyak 9 menit 22 Detik per orang. Selain itu, statistik dari SimiliarWeb [9] juga menerangkan bahwa $60,27 \%$ pengunjung mengetikkan url http://m.detik.com secara langsung tanpa melalui website google terlebih dahulu. Sehingga dapat disimpulkan bahwa website DetikCom sudah cukup populer dikalangan masyarakat. DetikCom adalah pelopor website berita mobile dan tertua di Indonesia. DetikCom didirikan pada 9 Juli 1998 dan hingga kini masih bertahan. DetikCom memiliki target audiens yang luas, sehingga rentang usia pembaca website DetikCom sangat 
bervariasi. Hal ini dikarenakan DetikCom mempunyai sub berita yang banyak, dari ekonomi, politik, kuliner, gosip selebriti, teknologi informasi, olahraga, kesehatan, otomotif, traveling pariwisata, dan gaya hidup.
SUS terdiri dari sepuluh pertanyaan yang masing-masing pertanyaan memiliki skala lima poin yang berkisar dari "Sangat Tidak Setuju" hingga "Sangat Setuju." Terdapat lima pernyataan positif dan lima pernyataan negatif. Berikut adalah sepuluh pernyataan pada kuesioner SUS:

Tabel 1. System Usability Scale (SUS) hasil terjemahan item

\begin{tabular}{|c|c|c|c|c|c|c|}
\hline No & Pertanyaan & $\begin{array}{l}\text { Sangat } \\
\text { tidak } \\
\text { setuju }\end{array}$ & $\begin{array}{l}\text { Tidak } \\
\text { setuju }\end{array}$ & $\begin{array}{c}\text { Ragu- } \\
\text { ragu }\end{array}$ & Setuju & $\begin{array}{l}\text { Sangat } \\
\text { setuju }\end{array}$ \\
\hline $\mathbf{1}$ & $\begin{array}{l}\text { Saya sering membaca berita pada } \\
\text { website DetikCom di smartphone. }\end{array}$ & 1 & 2 & 3 & 4 & 5 \\
\hline 2 & $\begin{array}{l}\text { Menurut saya, website DetikCom di } \\
\text { smartphone terlalu rumit/kompleks. }\end{array}$ & 1 & 2 & 3 & 4 & 5 \\
\hline 3 & $\begin{array}{l}\text { Menurut saya, website DetikCom di } \\
\text { smartphone mudah digunakan. }\end{array}$ & 1 & 2 & 3 & 4 & 5 \\
\hline 4 & $\begin{array}{l}\text { Saya perlu bantuan seseorang yang } \\
\text { ahli/mengerti bagaimana menggunakan } \\
\text { website DetikCom di smartphone. }\end{array}$ & 1 & 2 & 3 & 4 & 5 \\
\hline 5 & $\begin{array}{l}\text { Menurut saya, fitur/menu yang ada pada } \\
\text { website DetikCom di smartphone } \\
\text { berhubungan satu dan lainnya dan } \\
\text { membantu dalam membaca berita. }\end{array}$ & 1 & 2 & 3 & 4 & 5 \\
\hline 6 & $\begin{array}{l}\text { Menurut saya, fitur/menu yang ada pada } \\
\text { website DetikCom di smartphone tidak } \\
\text { konsisten. }\end{array}$ & 1 & 2 & 3 & 4 & 5 \\
\hline 7 & $\begin{array}{l}\text { Menurut saya, orang awam akan dengan } \\
\text { cepat memahami dan mudah } \\
\text { menggunakan website DetikCom di } \\
\text { smartphone untuk membaca berita. }\end{array}$ & 1 & 2 & 3 & 4 & 5 \\
\hline 8 & $\begin{array}{l}\text { Menurut saya, website DetikCom di } \\
\text { smarphone terlalu sulit digunakan. }\end{array}$ & 1 & 2 & 3 & 4 & 5 \\
\hline 9 & $\begin{array}{l}\text { Saya merasa nyaman saat membaca } \\
\text { berita pada website DetikCom di } \\
\text { smartphone. }\end{array}$ & 1 & 2 & 3 & 4 & 5 \\
\hline 10 & $\begin{array}{l}\text { Saya harus mempelajari banyak hal } \\
\text { sebelum menggunakan website } \\
\text { DetikCom di smartphone. }\end{array}$ & 1 & 2 & 3 & 4 & 5 \\
\hline
\end{tabular}




\section{HASIL DAN PEMBAHASAN}

\section{Reliabilitas Total dan Aspek}

Untuk mengetahui reliabilitas dari SUS ini, peneliti memasukan semua data jawaban kuesioner responden dan mencari nilai $\alpha$ cronbach's. Kuesioner dapat dikatakan memiliki tingkat reliabilitas yang baik apabila nilai $\alpha$ cronbach's mendekati 1 , dan nilai $\alpha$ cronbach yang dapat dikatakan diterima adalah sebesar 0,7. Untuk $\alpha$ cronbach total dari kuesioner SUS, nilai $\alpha$ yang didapat adalah sebesar 0,847 .

Tabel 2. Reliabilitas Total Kuesioner

\begin{tabular}{lll}
\hline \multicolumn{3}{c}{ Reliability Statistics } \\
\hline $\begin{array}{l}\text { Cronbach's } \\
\text { Alpha }\end{array}$ & $\begin{array}{l}\text { Cronbach's Alpha } \\
\text { Based on } \\
\text { Standardized Items }\end{array}$ & $\begin{array}{l}\text { N of } \\
\text { Items }\end{array}$ \\
\hline $\mathbf{8 4 7}$ & .849 & 10 \\
\hline
\end{tabular}

Dengan melihat nilai $\alpha$ cronbach's tersebut dapat dikatakan bahwa reliabilitas dari kuesioner SUS ini dapat diterima. Untuk menghidari permasalahan gender bias pada sebuah kuesioner, perhitungan reliabilitas juga dilakukan berdasarkan gender. Terdapat 25 responden laki-laki dan 30 responden perempuan pada penelitian ini. Dari hasil penghitungan reliabilitas kuesioner pada responden laki-laki, $\alpha$ cronbach's menunjukkan nilai 0,86 dan pada responden perempuan nilai $\alpha$ cronbach's adalah 0,838 . Untuk itu, dapat disimpulkan bahwa reliabilitas total dari kuesioner SUS ini dapat diterima, dan tidak ada permasalahan yang signifikan apabila kuesioner ini diujikan kepada responden laki-laki maupun perempuan.

Tabel 3. Pesebaran Responden dan $\alpha$ Cronbach

\begin{tabular}{lcc}
\hline Responden & n & $\boldsymbol{\alpha}$ cronbach's \\
\hline $\begin{array}{l}\text { Semua } \\
\text { Responden }\end{array}$ & 55 & 0,847 \\
\hline $\begin{array}{l}\text { Responden } \\
\text { Perempuan }\end{array}$ & 30 & 0,838 \\
\hline $\begin{array}{l}\text { Responden } \\
\text { Laki-laki }\end{array}$ & 25 & 0,861 \\
\hline
\end{tabular}

\section{Validitas dan Daya Beda Item}

Uji validitas bertujuan untuk mengetahui kevalidan atau kesesuaian kuesioner dalam penelitian untuk memperoleh data dari responden. Pengujian kevalidan atau kesesuain kuesioner dalam penelitian ini adalah dengan menggunakan Uji Validitas Product Momen Pearson Correlation. Uji Validitas ini menggunakan prinsip mengkorelasikan atau menghubungkan antara masing-masing skor item dengan skor total yang diperoleh dalam penelitian.

Perbandingan koefisien validitas $(r)$ pada tabel dan $r$ hitung merupakan dasar pengambilan keputusan untuk menyatakan suatu item memiliki tingkat kevalidan yang baik. Nilai $r$ ini dipengaruhi oleh jumlah responden. Pada penelitian ini, jumlah respondennya sebanyak 55 orang. Jika mengambil nilai $r$ dari tabel dengan derajat bebas $\mathrm{n}-2$ dimana $\mathrm{n}$ adalah jumlah responden, maka dengan derajat bebas 53 diperoleh nilai $r=0,2241$.

Dengan membandingkan nilai rhitung dengan nilai $r$ tabel maka dengan mudah akan ditemukan tingkat validitas dari setiap item pada sebuah kuesioner. Pada penelitian ini, jika melihat nilai $r$ table $=0,2241$ maka, rhitung yang memiliki nilai dibawah 0,2241 dapat dikatakan sebagai item yang tidak valid dan harus dihapuskan agar tingkat reliabilitas kuesioner dapat menjadi semakin baik. 
Tabel 4. Nilai Koefisien Validitas Setiap Item

\begin{tabular}{ccccc}
\hline \multicolumn{5}{c}{ Item-Total Statistics } \\
\hline & $\begin{array}{c}\text { Scale Mean if } \\
\text { Item Deleted }\end{array}$ & $\begin{array}{c}\text { Scale } \\
\text { Variance if } \\
\text { Item Deleted }\end{array}$ & $\begin{array}{c}\text { Corrected } \\
\text { Item-Total } \\
\text { Correlation }\end{array}$ & $\begin{array}{c}\text { Cronbach's } \\
\text { Alpha if Item } \\
\text { Deleted }\end{array}$ \\
\hline Item_1 & 32.0000 & 27.111 & .268 & .856 \\
\hline Item_2 & 32.1273 & 23.409 & .768 & .813 \\
\hline Item_3 & 31.8545 & 24.608 & .596 & .828 \\
\hline Item_4 & 31.0545 & 26.423 & .477 & .839 \\
\hline Item_5 & 31.8545 & 26.349 & .438 & .842 \\
\hline Item_6 & 32.2000 & 24.274 & .630 & .825 \\
\hline Item_7 & 31.9091 & 23.936 & .558 & .832 \\
\hline Item_8 & 31.6182 & 23.648 & .692 & .819 \\
\hline Item_9 & 31.8909 & 23.543 & .657 & .822 \\
\hline Item_10 & 31.6000 & 24.504 & .437 & .847 \\
\hline
\end{tabular}

Dengan melihat hasil $r$ pada setiap item yang ada dapat disimpulkan bahwa nilai $r$ pada setiap item melebihi 0,2241 sehingga dapat dikatakan bahwa semua item yang ada pada penelitian ini adalah valid. Namun, terdapat satu item, yakni item_1 yang memiliki nilai $r$ 0,268 . Walaupun nilai tersebut masih berada di atas $r$ tabel yang harus dilampaui, namun bedanya relatif kecil sehingga perlu ada pengkajian ulang untuk memasukan Item_1 dalam kuesioner SUS. Item_1 pada keusioner SUS ini adalah pernyataan mengenai kuantitas seseorang dalam membuka dan membaca berita melalui website DetikCom. Jika melihat nilai koefisien validitas yang diperoleh dari Item_1, bisa dikatakan bahwa pengukuran usability website berita online tidak sesuai jika dinyatakan dengan kuantitas dalam mengakses atau membuka website berita online tersebut. Apabila item_1 tersebut dihilangkan maka nilai reliabilitas dari kuesioner ini akan semakin meningkat, dari yang sebelumnya 0,847 menjadi 0,856 .

Dengan demikian, dapat disimpulkan bahwa item_1 harus dipertimbangkan kembali untuk masuk ke dalam kuesioner.

\section{KESIMPULAN}

Dari hasil pengolahan reliabilitas dan validitas pada SUS, dapat dikatakan bahwa kuesioner SUS memiliki tingkat reliabilitas yang cukup baik. Demikian pula pada tingkat validitas kuesioner ini. Semua item yang ada pada kuesioner SUS ini memiliki koefisien validitas di atas koefien validitas tabel Product Momen Pearson Correlation. Namun dalam penyusunan kuesioner selanjutnya, peneliti harus lebih berhati-hati terutama ketika memasukan indikator kuantitas mengakses website dan kuantitas membaca berita online untuk mengetahui usability website berita mobile.

\section{REFERENSI}

[1] Syarief, A., \& Hibino, H. 2005. Look and Feel: Examining the Power of Website Design Appearance across Site Types. In MX Design Conference. 1-10.

[2] U.S. Department of Health \& Human Services. Usability Basics. http://www.usability.gov. Diakses bulan April 2016

[3] Nielsen, J. 2012. Usability 101: Introduction to Usability.

[4] Norman, D. A. 2004. Emotional Design: Why We Love (or Hate) Everyday Things. Basic books.

[5] Brooke, J. 1996. SUS-A quick and dirty usability scale. Usability evaluation in industry, 189(194), 4-7.

[6] APJII. Profil Pengguna Internet Indonesia 2014. https://www.apjii.or.id/content/read/39/27 /profil-pengguna-internet-indonesia-2014. Diakses bulan April 2016. 
[7] Phone Scoop. Database of Mobile Phone Information.

http://www.phonescoop.com/glossary/

term.php? gid $=131$. Diakses bulan April 2016.

[8] Alexa Internet Inc., https://www.alexa.com/siteinfo/detik.com. Diakses bulan April 2016.

[9] SimilarWeb Ltd., https://www.similarweb.com/website/ detik.com. Diakses bulan April 2016. 